\title{
Comparison of Sole-source and Supplemental Lighting on Callus Formation and Initial Rhizogenesis of Gaura and Salvia Cuttings
}

\author{
W. Garrett Owen and Roberto G. Lopez ${ }^{1}$ \\ Department of Horticulture, Michigan State University, 1066 Bogue Street, \\ East Lansing, MI 48824
}

Additional index words. herbaceous perennials, HPS, LEDs, light quality, propagation, root development

\begin{abstract}
Variability in outdoor daily temperatures and photosynthetic daily light integrals (DLIs) from early spring to late fall limits the ability of propagators to accurately control propagation environments to consistently callus, root, and yield compact herbaceous perennial rooted liners. We evaluated and compared the effects of sole-source lighting (SSL) delivered from red (R) and blue (B) light-emitting diodes (LEDs) to supplemental lighting (SL) provided by high-pressure sodium (HPS) lamps on herbaceous perennial cutting morphology, physiology, and growth during callusing and initial rhizogenesis. Cuttings of perennial sage (Salvia nemorosa L. 'Lyrical Blues') and wand flower (Gaura lindheimeri Engelm. and A. Gray 'Siskiyou Pink') were propagated in a walk-in growth chamber under multilayer SSL provided by $L E D s$ with $[R(660 \mathrm{~nm})]$ : [B (460 nm)] light ratios $(\%)$ of 100:0 $\left(R_{100}: B_{0}\right), 75: 25\left(R_{75}: B_{25}\right), 50: 50\left(R_{50}: B_{50}\right)$, or 0:100 $\left(R_{0}: B_{100}\right)$ delivering $60 \mu \mathrm{mol} \cdot \mathrm{m}^{-2} \cdot \mathrm{s}^{-1}$ for 16 hours (total DLI of $\left.3.4 \mathrm{~mol} \cdot \mathrm{m}^{-2} \cdot \mathrm{d}^{-1}\right)$. In a glass-glazed greenhouse (GH control), cuttings were propagated under ambient solar light and day-extension SL provided by HPS lamps delivering $40 \mu \mathrm{mol} \cdot \mathrm{m}^{-2} \cdot \mathrm{s}^{-1}$ to provide a 16-hour photoperiod (total DLI of $3.3 \mathrm{~mol} \cdot \mathrm{m}^{-2} \cdot \mathrm{d}^{-1}$ ). At 10 days after sticking cuttings, callus diameter and rooting percentage were similar among all light-quality treatments. For instance, callus diameter, a measure of growth, of wand flower cuttings increased from an average $1.7 \mathrm{~mm}$ at stick (0 day) to a range of 2.7 to $2.9 \mathrm{~mm}$ at 10 days after sticking, regardless of lighting treatment. Relative leaf chlorophyll content was generally greater under SSL $R_{75}: B_{25}$ or $R_{50}: B_{50}$ than all other light-quality treatments. However, stem length of perennial sage and wand flower cuttings propagated under $\operatorname{SSL} \mathbf{R}_{50}: B_{50}$ at 10 days were $21 \%$ and $30 \%$ shorter and resulted in $50 \%$ and $8 \%$ greater root biomass, respectively, compared with those under SL. The herbaceous perennial cuttings propagated in this study under SSL $\mathbf{R}_{50}: B_{50}$ were of similar quality or more compact compared with those under SL, indicating that callus induction and initial rooting can occur under LEDs in a multilayer SSL propagation system.
\end{abstract}

Herbaceous perennials are propagated from seed (plugs), cuttings (liners), divisions, and tissue-cultured plantlets, and in 2015 had a reported wholesale value of $\$ 120$ million for the 15 top-producing states (U.S. Department of Agriculture, 2016). Although herbaceous perennials can be successfully and economically propagated by seed, many are vegetatively propagated by shoot-tip, stem, basal, rhizome, or root cuttings, thus maintaining genetic uniformity, producing sterile cultivars, and hasten-

Received for publication 8 Aug. 2018. Accepted for publication 17 Dec. 2018.

We gratefully acknowledge Dr. Brian Jackson, Dr. William Fonteno, and Laura Kaderabek for propagation substrate analysis. We thank Ball Horticultural Co., Inc. for plant material; Sun Gro Horticulture for substrate; Ludvig Svensson US, Inc. for shade cloth; J.R. Peters, Inc. for fertilizer; and the Fred C. Gloeckner Foundation, Inc. and the New Hampshire Plant Growers Association for financial support. The use of trade names in this publication does not imply endorsement by Michigan State University of products named or criticism of similar ones not mentioned.

${ }^{1}$ Corresponding author. E-mail: rglopez@msu.edu temperature-dependent, thereby effecting AR formation (ARF) in cuttings. In addition, outdoor DLIs during late winter to early spring months are relatively low ( 5 to $20 \mathrm{~mol} \cdot \mathrm{m}^{-2} \cdot \mathrm{d}^{-1}$ ) compared with summer and fall months (30 to $50 \mathrm{~mol} \cdot \mathrm{m}^{-2} \cdot \mathrm{d}^{-1}$; Korczynski et al., 2002) and can be reduced by $50 \%$ or more from the greenhouse glazing material (Hanan, 1998) with further reductions from greenhouse infrastructure shading, white wash, and shade curtains (Lopez and Runkle, 2008). Although low DLIs $\left(\leq 5 \mathrm{~mol} \cdot \mathrm{m}^{-2} \cdot \mathrm{d}^{-1}\right)$ during the early stages of propagation may be beneficial for minimizing stress and developing callus, excessively low DLIs $\left(\leq 2 \mathrm{~mol} \cdot \mathrm{m}^{-2} \cdot \mathrm{d}^{-1}\right)$ can result in little to no ARF in cuttings. Overall, these seasonal variations pose a challenge to maintain consistent callusing and rooting of herbaceous perennials (Owen and Lopez, 2016). Therefore, additional temperature management and SL may be necessary during propagation.

Previous research has investigated the effects of DLI and SL from high-pressure sodium (HPS) lamps and LEDs during AR development and subsequent rhizogenesis of numerous genera of vegetatively propagated annual bedding plants (Currey et al., 2012; Hutchinson et al., 2012; Lopez and Runkle, 2008). In controlled environments, the effects of SSL provided by LEDs during seedling (plug) propagation (Randall and Lopez, 2015; Wollaeger and Runkle, 2015) and in vitro propagation (Budiarto, 2010; Gu et al., 2012; Jao et al., 2005) have been documented.

Ex vitro vegetative cutting propagation under SSL LEDs has been investigated for calibrachoa (Calibrachoa Llave and Lex. 'MiniFamous Neo Royal Blue'; Olschowski et al., 2016), English lavender (Lavandula angustifolia Mill. 'Hidcote'; Christiaens et al., 2015), garden mum (Chrysanthemum $\times$ morifolium 'Orlando'; Christiaens et al., 2015), sweet basil (Ocimum basilicum L.; Lim and Eom, 2013), and four genera of woody ornamentals (Christiaens et al., 2015; Van Dalfsen and Slingerland, 2012). These studies examined the photomorphogenic responses to monochromatic and dichromatic light spectra. For instance, Christiaens et al. (2015) propagated garden mum cuttings under SSL LEDs delivering $60 \mu \mathrm{mol} \cdot \mathrm{m}^{-2} \cdot \mathrm{s}^{-1}$ (DLI of $\left.4.1 \mathrm{~mol} \cdot \mathrm{m}^{-2} \cdot \mathrm{d}^{-1}\right)$ of $\mathrm{R}(660 \mathrm{~nm})$ :B $(460 \mathrm{~nm})$ light ratios $(\%)$ of $\mathrm{R}_{100}: \mathrm{B}_{0}, \mathrm{R}_{90}: \mathrm{B}_{10}$, $\mathrm{R}_{50}: \mathrm{B}_{50}, \mathrm{R}_{10}: \mathrm{B}_{90}$, or $\mathrm{R}_{0}: \mathrm{B}_{100}$. They determined root dry mass (RDM) of garden mum cuttings propagated under $\mathrm{R}_{100}: \mathrm{B}_{0}$ or $\mathrm{R}_{0}: \mathrm{B}_{100}$ to be $171 \%$ to $200 \%$ greater, respectively, than for cuttings propagated under all dichromatic ratios tested. In another study, Olschowski et al. (2016) propagated calibrachoa cuttings under SSL LEDs delivering $80 \mu \mathrm{mol} \cdot \mathrm{m}^{-2} \cdot \mathrm{s}^{-1}$ of $\mathrm{R}_{100}: \mathrm{B}_{0}$ or $\mathrm{R}_{0}: \mathrm{B}_{100}$ or HPS lamps delivering $80 \mu \mathrm{mol} \cdot \mathrm{m}^{-2} \cdot \mathrm{s}^{-1}$ to provide a DLI of $4.6 \mathrm{~mol} \cdot \mathrm{m}^{-2} \cdot \mathrm{d}^{-1}$ and maintained $95 \% \mathrm{rel}-$ ative humidity $(\mathrm{RH})$ and $24{ }^{\circ} \mathrm{C}$ air temperature. After $21 \mathrm{~d}$, they observed calibrachoa cuttings propagated under SSL LEDs exhibited significantly shorter roots and had smaller shoot dry mass (SDM) and RDM compared with cuttings propagated under HPS lamps. 
Although the foci of these experiments were only to determine ARF and subsequent root and shoot growth and development, literature determining the effects of SSL LEDs on callus formation and growth in vegetative cuttings has not been documented. Methods to assess in vitro callus formation and growth include fresh and dry callus mass, surface area and volume measurements, visual comparisons, cellular quantification, mitotic indices, and callus respiration (Mottley and Keen, 1987; Sathyanarayana and Varghese, 2007). To date, scientific methods have not been established to measure and quantify ex vitro callus formation and growth.

There is little known about the effects of light quality from SSL on callus formation and growth and on initial ARF during vegetative propagation of herbaceous perennials. The recent interest in SSL LEDs for ornamental seedling production, combined with the potential use for vegetative cutting propagation, provides a unique opportunity to investigate the impact of spectra-specific SSL applications. In addition, a multilayer vertical system for ex vitro cutting propagation provides propagators a controlled environment (light and temperature) to uniformly callus and root vegetative cuttings, maintain consistent liner quality, and maximize space efficiency. Therefore, our objectives were to quantify and compare the effects of SSL from LEDs providing four different light qualities to SL from HPS lamps on callus formation and growth and on early subsequent rhizogenesis of herbaceous perennial cuttings. In addition, we aim to establish new methodologies to quantify callus formation and growth in vegetatively propagated herbaceous perennial cuttings.

\section{Materials and Methods}

Plant material and culture. On 9 (Rep. 1) and 24 Mar. (Rep. 2) unrooted herbaceous cuttings of perennial sage (Salvia nemorosa L. 'Lyrical Blues') and wand flower (Gaura lindheimeri Engelm. and A. Gray 'Siskiyou Pink') were received from a commercial cutting supplier (Darwin Perennials, Ball Horticultural Co., West Chicago, IL). Species were selected according to the survey conducted by Owen and Lopez (2016). For each species, cuttings with similar stem length, stem caliper, node, and leaf numbers were selected. At initiation $(0 \mathrm{~d})$, average stem length, stem caliper, node number, and total leaf area (TLA) for perennial sage were $23.6 \mathrm{~mm}, 2.5 \mathrm{~mm}, 4.4$ nodes, and $27.6 \mathrm{~cm}^{2}$, respectively. Average stem length, stem caliper, node number, and TLA of wand flower at initiation were $35.4 \mathrm{~mm}, 1.4 \mathrm{~mm}, 4.4$ nodes, and $6.6 \mathrm{~cm}^{2}$, respectively.

Industry standard, 72-cell propagation trays (30.7 $\mathrm{mL}$ individual cell volume, $54 \mathrm{~cm} \times 28$ $\mathrm{cm} \times 6 \mathrm{~cm}$; T.O. Plastics, Inc., Clearwater, $\mathrm{MN})$ were filled with a 50:50 (v/v) commercial soilless substrate composed of (by volume) $65 \%$ peat, $20 \%$ perlite, and $15 \%$ vermiculite (Fafard 2; Sun Gro Horticulture, Agawam, MA) and $50 \%$ coarse perlite (Strong-Lite Coarse Perlite; Sun Gro Horticulture, Bellevue,
WA). Propagation substrate physical properties were determined using three representative samples that were analyzed using the North Carolina State University Porometer Procedure (Fonteno et al., 1995). Physical properties of the propagation substrate were (by volume) $19.6 \% \pm 0.4 \%$ air space, $82.1 \% \pm 0.5 \%$ total porosity, $62.5 \% \pm 0.2 \%$ container capacity, and $0.11 \mathrm{~g} \cdot \mathrm{cm}^{-3}$ bulk density. Trays were irrigated to container capacity with water supplemented with 93\% sulfuric acid (Brenntag, Reading, $\mathrm{PA})$ at $0.08 \mathrm{mg} \cdot \mathrm{L}^{-1}$ to reduce alkalinity from 400 to $100 \mathrm{mg} \cdot \mathrm{L}^{-1}$ calcium carbonate $\left(\mathrm{CaCO}_{3}\right)$ and $\mathrm{pH} 7.4$ to a range of 5.8 to 6.2 . After trays were allowed to drain, 360 cuttings of perennial sage and wand flower were individually placed in trays on $16 \mathrm{~cm}^{2}$ centers.

Propagation trays were placed in trays without drainage holes $(54 \mathrm{~cm} \times 28 \mathrm{~cm} \times 3 \mathrm{~cm}$; T.O. Plastics, Inc.) filled with triple-rinsed aggregates of a calcined, nonswelling illite and silica clay $\left(\mathrm{MVP}^{\circledR}\right.$, Turface $^{\circledR}$; PROFILE Products LLC, Buffalo Grove, IL) with a $\mathrm{pH}$ of 5.9 and electrical conductivity (EC) of $0.0 \mathrm{~S} \cdot \mathrm{m}^{-1}$ (HI 9813-6; Hanna Instruments, Woonsocket, RI). Each tray received $300 \mathrm{~mL}$ of deionized water with an average $\mathrm{pH}, \mathrm{EC}$, and alkalinity (HI775 Freshwater alkalinity handheld colorimeter; Hanna Instruments) of 5.6, 0.0 S.m ${ }^{-1}$, and $52.3 \mathrm{mg} \cdot \mathrm{L}^{-1} \mathrm{CaCO}_{3}$, respectively. The trays were covered with a clear, plastic humidity dome $(54 \mathrm{~cm} \times 28 \mathrm{~cm} \times$ $15 \mathrm{~cm}$; Acro Dome, Acro Plastics, LTD., Edmonton, Alberta, Canada).

Growth chamber propagation environment. Trays were placed on one of two stainless steel vertical structures $(1.23 \mathrm{~m}$ long $\times 61 \mathrm{~cm}$ wide $)$ with two shelves spaced $50 \mathrm{~cm}$ apart in a walk-in growth chamber (C5 Control System; Environmental Growth Chambers, Chagrin Falls, OH). Each shelf was insulated with cellofoam expanded polystyrene (EPS) boards faced with a reflective foil $(1.2 \mathrm{~m} \times 2.4 \mathrm{~m} \times 2.3 \mathrm{~cm}$; Polyshield $^{\circledR}$, Whiteland, IN) and covered with a heavy-duty, commercial-quality rubber heating mat $(1.5 \mathrm{~m} \times 56 \mathrm{~cm}$, Pro-Grow propagation mat; Pro-Grow Supply Corp., Brookfield, WI). Each heating mat was controlled independently with a thermostat (GC-4 Gro-control thermostat; ProGrow Supply Corp.) and set to maintain a propagation substrate temperature of $24{ }^{\circ} \mathrm{C}$. The air temperature and $\mathrm{RH}$ set points were $21{ }^{\circ} \mathrm{C}$ and $70 \% / 80 \%$ day/night, respectively.

SSL was delivered from one of four LED arrays (Orbital Technologies Corporation, Madison, WI) providing monochromatic $\mathrm{R}$ [100:0 R $\left.(660 \mathrm{~nm}): \mathrm{B}(460 \mathrm{~nm}) ; \mathrm{R}_{100}: \mathrm{B}_{0}\right]$, monochromatic $\mathrm{B}\left(0: 100 \mathrm{R}: \mathrm{B} ; \mathrm{R}_{0}: \mathrm{B}_{100}\right)$, or a combination of $\mathrm{R}$ and $\mathrm{B}\left[75: 25 \mathrm{R}: \mathrm{B}\left(\mathrm{R}_{75}: \mathrm{B}_{25}\right)\right.$ or 50:50 $\left(\mathrm{R}_{50}: \mathrm{B}_{50}\right)$ ] light (Table 1). Sole-source LED light delivered a photosynthetic photon flux density $(P P F D)$ of $\approx 60 \mu \mathrm{mol} \cdot \mathrm{m}^{-2} \cdot \mathrm{s}^{-1}$ under a 16-h photoperiod from 0600 to $2200 \mathrm{HR}$ to achieve a target DLI of $\approx 3.4 \mathrm{~mol} \cdot \mathrm{m}^{-2} \cdot \mathrm{d}^{-1}$. The $\mathrm{R}: \mathrm{B}$ ratio and the estimated phytochrome photoequilibrium $(\varphi)$ was calculated according to Sager et al. (1988) by multiplying the PPFD at each wavelength against the relative absorption for phytochrome red $\left(\mathrm{P}_{\mathrm{r}}\right)$ and phytochrome far$\operatorname{red}\left(\mathrm{P}_{\mathrm{fr}}\right)\left(\varphi=\mathrm{P}_{\mathrm{fr}} / \mathrm{P}_{\mathrm{r}}+\mathrm{P}_{\mathrm{fr}} ;\right.$ Table 1). A nonreflective blackout cloth was used to prevent light pollution between treatments. Treatments were randomized within the two shelves between replications.

Greenhouse propagation environment. Cuttings were placed on a propagation bench in a glass-glazed greenhouse ( $\mathrm{GH}$ control). Exhaust fan and evaporative-pad cooling, radiant hot water heating, and retractable shade curtains were controlled by an environmental control system (Maximizer Precision 10; Priva Computers Inc., Vineland Station, ON, Canada). The propagation bench was insulated with cellofoam EPS boards faced with a reflective foil $(1.2 \mathrm{~m} \times$ $2.4 \mathrm{~m} \times 2.3 \mathrm{~cm}$; Polyshield $\left.^{\circledR}\right)$. A closed-loop bench-top root-zone heating system was installed with microtubing that circulated hot water $\left(49^{\circ} \mathrm{C}\right)$ across the bench (Biotherm ${ }^{\circledR}$ Benchwarmer Kit; TrueLeaf Technologies, Petaluma, CA). To evenly distribute heat across the bench, the microtubing was covered with 2-mm galvanized sheet metal. To prevent heat loss and moisture accumulation, hightemperature aluminum foil tape $(6.3 \mathrm{~cm} \times$ $9.1 \mathrm{~m} ; 3 \mathrm{M}$, St. Paul, MN) was used to adhere the sheet metal to the bench. In addition, benches were covered with a 4-mil black construction film $(3 \mathrm{~m} \times 30.5 \mathrm{~m}$ roll; Blue Hawk, Poly-America, Grand Prairie, TX). Rootzone heating was controlled by a substrate thermistor probe (Biotherm ${ }^{\circledR}$ Benchwarmer Kit; TrueLeaf Technologies) and programmed for a propagation substrate temperature set point of $24^{\circ} \mathrm{C}$.

Cuttings were placed under fixed shadecloth providing 54\% shade (Solaro 5620 O-R-FR; Ludvig Svensson, Inc., Charlotte, NC) under ambient daylight supplemented with a total $P P F D$ of $\approx 58 \pm 8.1 \mu \mathrm{mol} \cdot \mathrm{m}^{-2} \cdot \mathrm{s}^{-1}$ at plant height [as measured with a quantum sensor (LI-190SL; LI-COR Biosciences, Lincoln, NE)] delivered from HPS lamps (PARsource Lighting Solutions, Petaluma, CA) from 0600 to 0800 and 1800 to $2200 \mathrm{HR}$ (16-h photoperiod). Woven shade curtains (OLS 50; Ludvig Svensson, Inc.) were retracted when the outdoor light intensity reached $\approx 500 \mu \mathrm{mol} \cdot \mathrm{m}^{-2} \cdot \mathrm{s}^{-1}$. The target greenhouse DLI, air temperature, and $\mathrm{RH}$ set points were 3.3 $\mathrm{mol} \cdot \mathrm{m}^{-2} \cdot \mathrm{d}^{-1}, 21^{\circ} \mathrm{C}$, and $80 \%$, respectively.

Environmental data collection. Light quality and $P P F D$ were measured at the beginning and end of each experimental replication by taking five individual spectral scans per treatment using a spectroradiometer (BLUE-Wave Miniature Spectrometer; StellarNet, Inc., Tampa, FL). Spectral quality of each SSL source and the GH control are provided in Fig. 1. For each species under each SSL LED and SL treatment, precision thermistors (ST-100; Apogee Instruments, Inc., Logan, UT) were used to measure the air temperature and substrate temperature under each humidity dome. Amplified quantum sensors (LI-COR Biosciences) measured $P P F D$ under each SSL treatment in the growth chamber and ambient and SL in the greenhouse. Measurements were recorded every $30 \mathrm{~s}$ and the average of each sensor was logged every $15 \mathrm{~min}$ by a data logger (Model CR1000; Campbell Scientific, Inc., Logan, UT). In the growth chamber, average air temperature, $\mathrm{RH}$, and $\mathrm{CO}_{2}$ concentration 


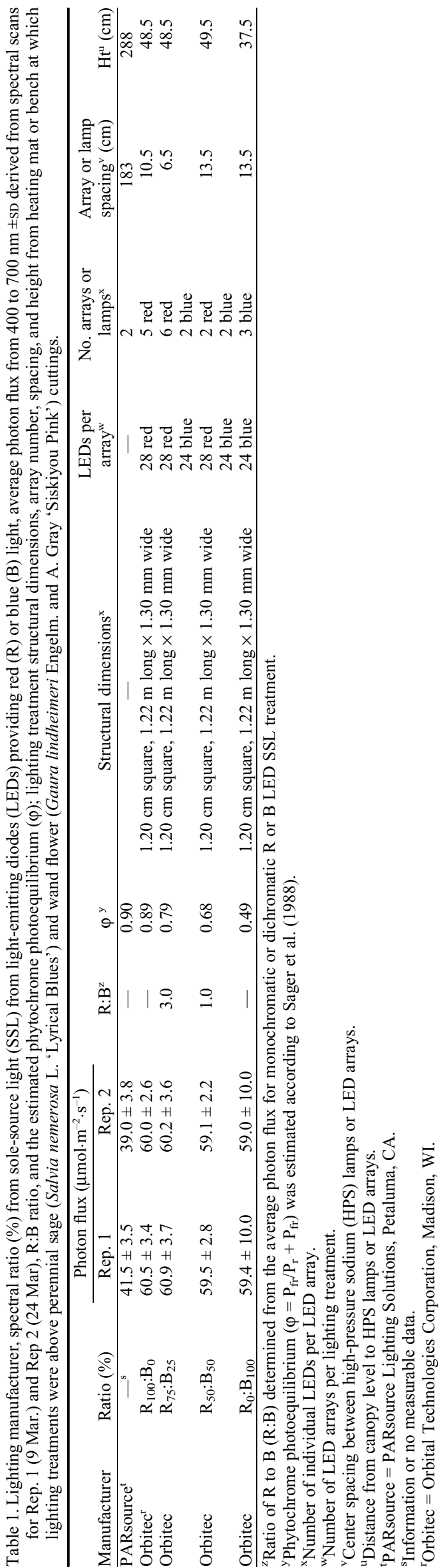

was logged every $15 \mathrm{~min}$ by a data logger (DL1 Datalogger; Environmental Growth Chambers). In the greenhouse, average air temperature and $\mathrm{RH}$ were logged every 10 min by an aspirated Priva temperature sensor and recorded by a computerized control system (Priva Computers Inc.). Environmental data for each species under each SSL LED or SL treatments for Reps 1 and 2 are reported in Table 2.

Callusing and rhizogenesis data collection and calculations. At stick ( $0 \mathrm{~d})$ and 2, 4, 6, 8, and $10 \mathrm{~d}$ after stick, 20 shoot-tip cuttings per species were evaluated for callus and adventitious rhizogenesis using repeated measures. Without causing damage, cuttings were removed and the propagation substrate was gently rinsed off of the basal end of each cutting. The percentage of rooted cuttings $(\%)=$ (number of cuttings exhibiting roots/ number of cuttings stuck) was calculated for each SSL or SL treatment. Callus diameter [(callus width + callus perpendicular width)/2] of each cutting was determined using a stainless steel drill gauge ruler-style (ToolUSA, Long Beach, CA) measuring 0.5 to $13.0 \mathrm{~mm}$. Total chlorophyll $(\mathrm{a}+\mathrm{b})$ content [i.e., relative chlorophyll content (RCC)] was estimated on three recently mature leaves using a SPAD meter (SPAD-502; Konica Minolta Sensing, Inc., Osaka, Japan) and was averaged across plant samples.

At stick (0 d) and 2, 4, 6, 8, and $10 \mathrm{~d}$ after sticking, six shoot-tip cuttings per species were removed from the propagation environments for destructive measurements. Stem length and caliper were measured from the base of the cutting to the apical meristem and below the lowest leaf with a digital caliper (digiMax; Wiha, Schönach, Germany), respectively. Node density (number) was recorded for each cutting. To determine whole-plant measurements, cuttings were destructively harvested. TLA was determined for each cutting by excising leaves from the petioles and placing each leaf in a leaf-area meter (LI-3000; LI-COR) three times and recording the mean. Roots were excised from the cutting and roots, stems (stems and petioles), and leaves were dried separately in an oven at $70^{\circ} \mathrm{C}$ for $3 \mathrm{~d}$. Roots, shoots, and leaves were then weighed (GR-200 Semimicro analytical balance; San Jose, CA) to determine RDM, SDM, and leaf dry mass (LDM), respectively. Total dry mass (TDM; TDM = $\mathrm{RDM}+\mathrm{SDM}+\mathrm{LDM}$ ) was also calculated for each cutting.

Experimental design and statistical analyses. In the growth chamber, the experiment was laid out in a randomized block design with light quality (four levels) and species (two levels) as factors. A propagation greenhouse served as a control for the SL treatment. The experiment was performed twice over time for each species (experimental replication). For each replication of the study, one 72-cell tray per species was subjected to each treatment, with individual cuttings within a tray serving as experimental units. For repeated measures, 10 (individual cuttings) per species per light-quality treatment 


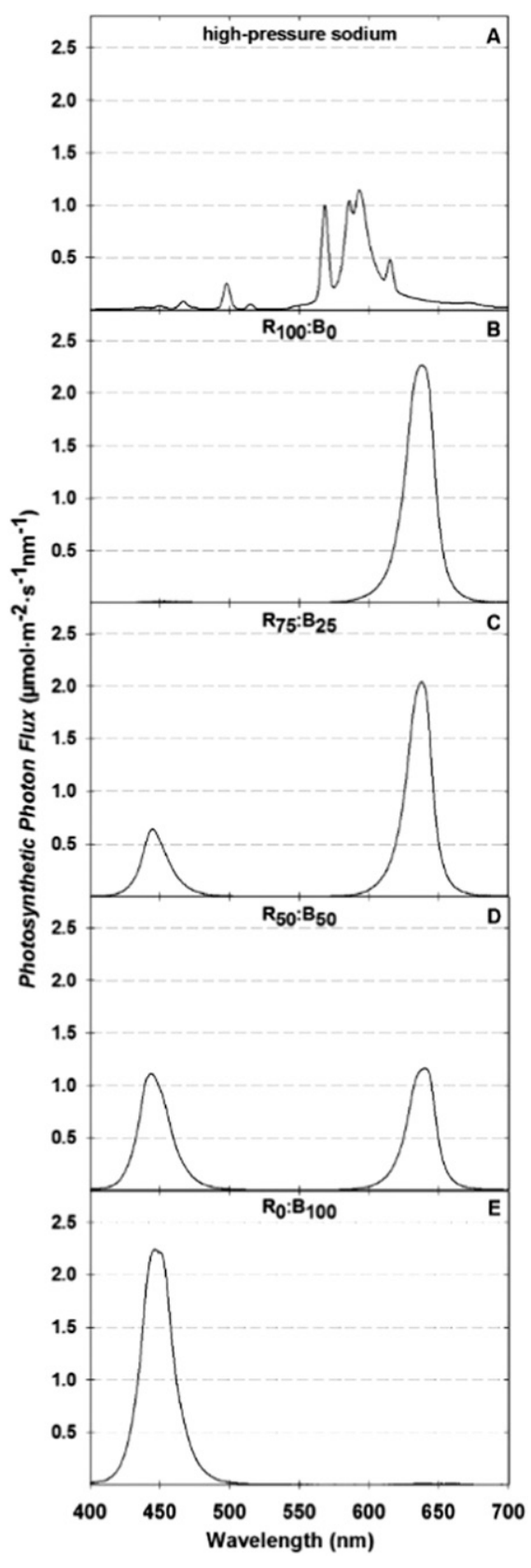

Fig. 1. (A-E) Spectral quality of supplemental light (SL) from high-pressure sodium (HPS) lamps in the greenhouse (A) or sole-source light (SSL) from light-emitting diodes (LED) arrays providing [R $(660 \mathrm{~nm})]$ : blue [B $(460 \mathrm{~nm})]$ light ratios $(\%)$ of 100:0 $\left[\mathrm{R}_{100}: \mathrm{B}_{0}(\mathrm{~B})\right], 75: 25\left[\mathrm{R}_{75}\right.$ : $\left.\mathrm{B}_{25}(\mathbf{C})\right], 50: 50\left[\mathrm{R}_{50}: \mathrm{B}_{50}\right.$ (D)], or 0:100 $\left[\mathrm{R}_{0}\right.$ : $\mathrm{B}_{100}$ (E)] at a $P P F$ from 400 to $700 \mathrm{~nm}$ of 60 $\mu \mathrm{mol} \cdot \mathrm{m}^{-2} \cdot \mathrm{s}^{-1}$ at cutting height in a growth chamber.

per experimental replication were used. For destructive measurements, six samples (individual cuttings) per species per light-quality treatment per experimental replication were used. Species were analyzed independently and data were pooled across experimental replications. Effects of light quality within SSL were analyzed using SAS (version 9.2; SAS Institute, Cary, NC) mixed model procedure (PROC MIXED) for analysis of variance, and means were separated between treatments using Tukey's honestly significant
(HSD) test at $P \leq 0.05$. A $t$ test was used to compare SSL treatment means with the SL treatment means.

\section{Results}

Morphology. At initiation (0 d), average callus diameter of perennial sage and wand flower cuttings was 2.7 and $1.7 \mathrm{~mm}$, respectively (Fig. 2A and B). Under each lightquality treatment, callus diameter of perennial sage exhibited a quadratic increase, whereas callus diameter of wand flower increased linearly from 2 to $10 \mathrm{~d}$ after sticking (data not shown). Regardless of light-quality treatment, callus growth of perennial sage reached a maximum diameter of 3.3 to $3.6 \mathrm{~mm}$ at $6 \mathrm{~d}$ (Fig. 2A). The largest measurable callus diameter of wand flower was recorded at $10 \mathrm{~d}$ and ranged from 2.7 to $2.9 \mathrm{~mm}$ (Fig. 2B).

Regardless of SSL treatment, rooting of perennial sage was similar and occurred $2 \mathrm{~d}$ earlier (at 8 d) than under SL (Table 3). At $10 \mathrm{~d}, 43 \%$ more perennial sage cuttings rooted under SSL $\mathrm{R}_{75}: \mathrm{B}_{25}$ LEDs than under SL. Rooting of wand flower occurred at $4 \mathrm{~d}$ under all treatments, with the greatest percentage observed under SSL $\mathrm{R}_{100}: \mathrm{B}_{0}$ LEDs; however, after $4 \mathrm{~d}$, rooting was similar regardless of light quality.

For both species, stem length (Table 3) and node number (data not shown) increased as days after sticking increased, although the magnitude of response varied under each light-quality treatment. Stem length of perennial sage cuttings was generally shorter as the proportion ( $\%$ ) of $\mathrm{R}$ light decreased from $100 \%\left(\mathrm{R}_{100}: \mathrm{B}_{0}\right)$ to $50 \%\left(\mathrm{R}_{50}: \mathrm{B}_{50}\right)$. For instance, at 6,8 , and $10 \mathrm{~d}$, perennial sage stem length was $24 \%, 28 \%$, and $45 \%$ shorter under $\mathrm{R}_{50}: \mathrm{B}_{50}$ than $\mathrm{R}_{100}: \mathrm{B}_{0}$ LEDs, respectively; and $18 \%, 18 \%$, and $27 \%$ shorter than cuttings propagated under SL, respectively (Table 3 ). Perennial sage TLA was unaffected by lightquality treatment (Table 3).

Under SL, wand flower stem length at 4 and $6 \mathrm{~d}$ was $23 \%$ and $26 \%$ shorter, respectively, than cuttings under SSL $\mathrm{R}_{100}: \mathrm{B}_{0}$ LEDs; however, by $10 \mathrm{~d}$, no differences were observed. At $10 \mathrm{~d}$, average stem length of wand flower under SSL $\mathrm{R}_{50}$ : $\mathrm{B}_{50}$ LEDs was $24 \%$ to $27 \%$ shorter than cuttings propagated under SSL $\mathrm{R}_{100}: \mathrm{B}_{0}$ and $\mathrm{R}_{75}: \mathrm{B}_{25}$ LEDs; and was $30 \%$ shorter than cuttings propagated under SL. Stem caliper and node number were unaffected when cuttings were propagated under SSL LEDs (data not shown). TLA of wand flower at 6 and $10 \mathrm{~d}$ under SSL $\mathrm{R}_{100}: \mathrm{B}_{0}$ LEDs was $29 \%$ and $27 \%$ smaller, respectively, than cuttings under SSL $\mathrm{R}_{75}: \mathrm{B}_{25}$ LEDs; and was $27 \%$ and $32 \%$ smaller compared with cuttings under SL (Table 2).

Physiology. At initiation (0 d), average RCC of perennial sage and wand flower cuttings was 26.4 and 40.1, respectively. As days after sticking increased from 2 to $10 \mathrm{~d}$, RCC of perennial sage cuttings under all SSL LED treatments exhibited a quadratic increase, whereas a linear response occurred for cuttings under SL (data not shown). RCC from 4 to $8 \mathrm{~d}$ was lowest under SSL $\mathrm{R}_{0}: \mathrm{B}_{100}$ LEDs and was $6 \%$ to $20 \%$ lower, respectively, than cuttings propagated under SL (Fig. 2C). At 10 d, RCC was $11 \%, 18 \%$, and $20 \%$ higher in perennial sage cuttings propagated under SSL $\mathrm{R}_{100}: \mathrm{B}_{0}, \mathrm{R}_{75}: \mathrm{B}_{25}$, or $\mathrm{R}_{50}: \mathrm{B}_{50}$ LEDs, respectively, than SL.

In wand flower, the magnitude of the RCC response to light-quality treatments varied over time (data not shown). In general, as the proportion (\%) of $\mathrm{R}$ light decreased from $100 \%$ to $50 \%$, RCC increased (Fig. 2D). For example, $10 \mathrm{~d}$ after stick, RCC increased by $13 \%$ under $\mathrm{R}_{50}: \mathrm{B}_{50}$ compared with $\mathrm{SSL}$ $\mathrm{R}_{100}: \mathrm{B}_{0}$ LEDs (Fig. 2D).

Growth. LDM and SDM (Table 3) and TDM (data not shown) increased with days after stick, although the magnitude of responses varied among light-quality treatments and species. Biomass accumulation for perennial sage was generally unaffected by light-quality treatment from 2 to $6 \mathrm{~d}$. At 8 and $10 \mathrm{~d}$, LDM, RDM, and TDM, but not SDM were significantly smaller when cuttings were propagated under SSL $\mathrm{R}_{0}: \mathrm{B}_{100}$ LEDs compared with all other SSL LED treatments. For instance, at $10 \mathrm{~d}$, LDM, RDM, and TDM of cuttings propagated under $\mathrm{R}_{0}: \mathrm{B}_{100}$ were $6 \%$ to $28 \%, 100 \%$ to $200 \%$, and $6 \%$ to $35 \%$ smaller, respectively, than cuttings under SSL $\mathrm{R}_{50}: \mathrm{B}_{50}$ or $\mathrm{R}_{100}: \mathrm{B}_{0}$ LEDs. At 8 and $10 \mathrm{~d}$, RDM of cuttings propagated under SSL $\mathrm{R}_{50}: \mathrm{B}_{50}$ LEDs was $40 \%$ and $50 \%$ larger, respectively, compared with cuttings under SL (Table 3). SDM was significantly influenced by SSL and increased linearly throughout propagation for all lightquality treatments (Table 3 ).

At 2 and $6 \mathrm{~d}$, LDM and SDM of wand flower cuttings were significantly different among SSL LED treatments, but at $10 \mathrm{~d}$, were similar regardless of light quality (Table 3 ). Compared with cuttings under SL, LDM at $10 \mathrm{~d}$ was $7.4,7.3$, and $4.3 \mathrm{mg}$ smaller when cuttings were propagated under SSL $\mathrm{R}_{100}: \mathrm{B}_{0}$, $\mathrm{R}_{50}: \mathrm{B}_{50}$, and $\mathrm{R}_{0}: \mathrm{B}_{100}$ LEDs, respectively. RDM was similar among all SSL LED treatments and increased linearly from 2 to $10 \mathrm{~d}$. At $10 \mathrm{~d}$, cuttings propagated under SSL $\mathrm{R}_{75}: \mathrm{B}_{25}$, $\mathrm{R}_{50}: \mathrm{B}_{50}$, and $\mathrm{R}_{0}: \mathrm{B}_{100}$ LEDs exhibited $17 \%$, $8 \%$, and $17 \%$ more root biomass, respectively, than under SL. TDM at $2 \mathrm{~d}$ was significantly smaller under $\mathrm{R}_{0}: \mathrm{B}_{100}$ than all other SSL LEDs, but at $10 \mathrm{~d}$, there were no significant differences (data not shown). However, TDM of cuttings propagated under SSL $\mathrm{R}_{100}: \mathrm{B}_{0}$ and $\mathrm{R}_{50}: \mathrm{B}_{50}$ LEDs were 9.7 and $10.2 \mathrm{mg}$ smaller, respectively, than cuttings propagated under SL (data not shown).

\section{Discussion}

In the current study, the degree to which LED SSL elicited photomorphogenic responses varied among species, but was generally found to have no effect on callus diameter, rooting percentage, stem caliper, node number, or SDM of perennial sage or wand flower cuttings at $10 \mathrm{~d}$ after stick (Fig. 2; Table 3). We did, however, observe some variability in callus formation, 
Table 2. Average propagation daily light integrals (PDLIs) were achieved by ambient solar light and supplemental light (SL) delivered from high-pressure sodium (HPS) lamps in the greenhouse or sole-source light (SSL) from light-emitting diodes (LEDs) in the growth chamber with red:blue light ratios (\%) of 100:0 $\left(\mathrm{R}_{100}: \mathrm{B}_{0}\right), 0: 100\left(\mathrm{R}_{0}: \mathrm{B}_{100}\right), 75: 25\left(\mathrm{R}_{75}: \mathrm{B}_{25}\right)$, or 50:50 ( $\left.\mathrm{R}_{50}: \mathrm{B}_{50}\right)$ with a 16-h photoperiod (0600 to $\left.2200 \mathrm{HR}\right)$. Average air, canopy, and substrate temperatures, and relative humidity during $10 \mathrm{~d}$ of propagation of perennial sage (Salvia nemorosa 'Lyrical Blues') and wand flower (Gaura lindheimeri Engelm. and A. Gray 'Siskiyou Pink') are also reported.

\begin{tabular}{|c|c|c|c|c|c|c|}
\hline \multirow[b]{2}{*}{ Propagation dates } & \multirow{2}{*}{$\begin{array}{l}\text { Light-quality } \\
\text { treatment }\end{array}$} & \multirow{2}{*}{$\begin{array}{c}\text { Avg PDLI } \\
\left(\mathrm{mol} \cdot \mathrm{m}^{-2} \cdot \mathrm{d}^{-1}\right)\end{array}$} & \multicolumn{3}{|c|}{ Temperature $\left({ }^{\circ} \mathrm{C}\right)$} & \multirow{2}{*}{$\begin{array}{l}\text { Relative humidity } \\
\text { [(\%) day/night }]\end{array}$} \\
\hline & & & Air & Canopy & Substrate & \\
\hline \multirow[t]{3}{*}{9 Mar. } & HPS & $3.0 \pm 0.9$ & $22.0 \pm 3.5$ & $24.9 \pm 1.3$ & $24.4 \pm 1.1$ & $75.4 \pm 16.9$ \\
\hline & $\mathrm{R}_{50}: \mathrm{B}_{50}$ & $3.3 \pm 0.1$ & & $22.6 \pm 1.4$ & $24.5 \pm 3.0$ & \\
\hline & $\mathrm{R}_{0}: \mathrm{B}_{100}$ & $3.4 \pm 0.1$ & & $24.3 \pm 1.9$ & $24.4 \pm 1.3$ & \\
\hline \multirow{4}{*}{24 Mar. } & HPS & $3.8 \pm 0.5$ & $22.4 \pm 3.1$ & $24.9 \pm 0.8$ & $24.7 \pm 0.9$ & $78.7 \pm 12.0$ \\
\hline & $\mathrm{R}_{50}: \mathrm{B}_{50}$ & $3.3 \pm 0.0$ & & $25.9 \pm 2.0$ & $24.3 \pm 2.1$ & \\
\hline & $\mathrm{R}_{0}: \mathrm{B}_{100}$ & $3.6 \pm 0.1$ & & $27.4 \pm 3.7$ & $24.8 \pm 2.1$ & \\
\hline & & & Wand flower & & & \\
\hline \multirow{4}{*}{9 Mar. } & HPS & $3.1 \pm 0.7$ & $22.0 \pm 3.5$ & $25.0 \pm 0.6$ & $24.0 \pm 0.8$ & $75.4 \pm 16.9$ \\
\hline & $\mathrm{R}_{100}: \mathrm{B}_{0}$ & $3.0 \pm 0.1$ & $21.0 \pm 0.1$ & $23.6 \pm 1.6$ & $24.5 \pm 2.1$ & $69.7 \pm 0.5 / 79.2 \pm 0.6$ \\
\hline & $\mathrm{R}_{75}: \mathrm{B}_{25}$ & $3.0 \pm 0.1$ & & $23.2 \pm 1.2$ & $24.2 \pm 1.8$ & \\
\hline & $\mathrm{R}_{50}: \mathrm{B}_{50}$ & $3.3 \pm 0.1$ & & $22.7 \pm 1.9$ & $24.4 \pm 2.6$ & \\
\hline 24 Mar. & $\mathrm{R}_{0}: \mathrm{B}_{100}$ & $3.6 \pm 0.1$ & & $22.8 \pm 1.0$ & $24.8 \pm 1.0$ & \\
\hline
\end{tabular}

rhizogenesis, and growth and development of cuttings from 2 to $8 \mathrm{~d}$ after stick.

Callus induction of perennial sage and wand flower was not influenced by light quality, as all cuttings exhibited callus at $2 \mathrm{~d}$ after stick (Fig. 2). In contrast, Budiarto (2010) reported increased callus induction of anthurium 'Violeta' and 'Pink Lady' plantlets grown in vitro for $30 \mathrm{~d}$ under $\mathrm{R}_{100}$ : $\mathrm{B}_{0}$ than $\mathrm{R}_{50}: \mathrm{B}_{50}$ and $\mathrm{R}_{0}: \mathrm{B}_{100}$ LEDs delivering 45 $\mu \mathrm{mol} \cdot \mathrm{m}^{-2} \cdot \mathrm{s}^{-1}$ (DLI of $2.6 \mathrm{~mol} \cdot \mathrm{m}^{-2} \cdot \mathrm{d}^{-1}$ ). In our study, perennial sage callus diameter, a measure of growth, was smallest at $2 \mathrm{~d}$ under $\mathrm{R}_{50}$ : $\mathrm{B}_{50}$ compared with SSL $\mathrm{R}_{100}: \mathrm{B}_{0}$ LEDs (Fig. 2); however, from 4 to $10 \mathrm{~d}$, calli formation was similar among all SSL LED treatments. Callus growth curves of in vitro grown miracle fruit [Gymnema sylvestre (Retz.) Schult.] were established by Ahmed et al. (2012), who identified and characterized four growth phases: 1) lag phase (15-25 d), callus initiation and proliferation; 2) exponential phase (25-35 d), increased growth; 3) stationary phase (35-45 d), maximum callus growth suggesting cellular membrane stabilization; and 4) decline phase $(45-55 \mathrm{~d})$, reduced callus growth. When these phases are taken together, callus growth of miracle fruit exhibited a sigmoidal growth curve, and when grown under R light (625 to $780 \mathrm{~nm}$ ), callus growth was significantly reduced compared with B light (455 to 495 $\mathrm{nm}$ ) (Ahmed et al., 2012). Although the phases established by Ahmed et al. (2012) described in vitro callus growth, they can be applied to ex vitro callus growth of cuttings. Results of perennial sage callus growth from our study can be characterized as having exponential and decline phases from 0 to 6 and 6 to $10 \mathrm{~d}$, respectively. This is consistent with our statistical analyses, which found callus diameter to exhibit an increasing qua- dratic response to light-quality treatments over time. For instance, callus growth of perennial sage cuttings propagated under SSL $\mathrm{R}_{100}: \mathrm{B}_{0}$ LEDs increased quadratically from 2.8 to $3.6 \mathrm{~mm}$ and declined from 3.6 to $3.3 \mathrm{~mm}$ at 0 to 6 and 6 to $10 \mathrm{~d}$ after sticking, respectively (data not shown). Analyses for wand flower found callus growth to increase linearly over time, thereby exhibiting lag and exponential phases from 0 to 2 and 2 to $10 \mathrm{~d}$, respectively. For instance, callus growth of wand flower cuttings propagated under SSL $\mathrm{R}_{50}: \mathrm{B}_{50}$ LEDs exhibited no change (1.8 to $1.8 \mathrm{~mm}$ ) at 0 to $2 \mathrm{~d}$ and increased linearly from 1.8 to $2.7 \mathrm{~mm}$ from 2 to $10 \mathrm{~d}$ after sticking, respectively (data not shown).

Callus formation, often a response to wound-induced rooting, is a precursor in some herbaceous genera for de novo AR initiation and ARF. Organization of AR initials give rise to AR primordia. When mature, these primordia disrupt the epidermis, emerge into the rhizosphere (da Costa et al., 2013), and further grow and develop into ARs. Light is a welldocumented environmental parameter that influences organ regeneration, such as ARs (Ikeuchi et al., 2016). There were no observable negative effects of LED SSL on AR initiation and ARF in both species. For perennial sage, rooting occurred under all SSL LED treatments $2 \mathrm{~d}$ earlier than under SL (10 d) (Table 3). In wand flower, AR initiation and ARF occurred at 4 and $6 \mathrm{~d}$, respectively, unaffected by SSL LEDs or SL (Table 3). The percentage of cuttings exhibiting $A R$ initiation at $4 \mathrm{~d}$ under $\mathrm{R}_{50}: \mathrm{B}_{50}$ and $\mathrm{R}_{0}: \mathrm{B}_{100}$ LED SSL was significantly lower than cuttings propagated under $\mathrm{SSL}_{100}: \mathrm{B}_{0} \mathrm{LEDs}$ and $\mathrm{SL}$, but by $10 \mathrm{~d}$, rooting percentage was similar regardless of light-quality treatment (Table 3). Previous studies have investigated the effects of photoreception of $\mathrm{R}$, far-red
(FR), and B light on ARF. Pfaff and Schopfer (1974) reported hypocotyl cuttings of mustard (Sinapis alba L.) seedlings grown ex vitro to regenerate ARs at the cutting surface when treated with short pulses of R $(568 \mathrm{~nm} ; 3.1$ $\left.\mu \mathrm{mol} \cdot \mathrm{m}^{-2} \cdot \mathrm{s}^{-1}\right)$ or continuous FR (740 nm; 17.5 $\left.\mu \mathrm{mol} \cdot \mathrm{m}^{-2} \cdot \mathrm{s}^{-1}\right)$ light. Further investigations by Pfaff and Schopfer (1980) revealed that phytochrome mediated the de novo formation of root primordia in mustard seedling hypocotyls near the cutting surface within 12 to $24 \mathrm{~h}$ after excision and that these seedlings exhibited increased primordium formation and ARs per cutting from 2 to $6 \mathrm{~d}$ and 3 to $7 \mathrm{~d}$ after excision, respectively. In another study, Fuernkranz et al. (1990) reported ARF of in vitro axillary shoots of black cherry (Prunus serotina Ehrh.) to be significantly reduced after $14 \mathrm{~d}$ under B light, delivering 15 to $22 \mu \mathrm{mol} \cdot \mathrm{m}^{-2} \cdot \mathrm{s}^{-1}$, and was completely inhibited at $36 \mu \mathrm{mol} \cdot \mathrm{m}^{-2} \cdot \mathrm{s}^{-1}$. Similarly, Stoutemyer and O'Rourke (1946) found B light at $\approx 75 \mu \mathrm{mol} \cdot \mathrm{m}^{-2} \cdot \mathrm{s}^{-1}$ to reduce ARF in early forsythia (Forsythia ovata Nakai) cuttings. These studies suggest that at $4 \mathrm{~d}$, ARF of wand flower cuttings propagated under SSL $\mathrm{R}_{100}$ : $\mathrm{B}_{0}$ LEDs and SL were initially influenced by phytochrome. Although, with the absence of FR light under SSL LEDs, ARF under SSL $\mathrm{R}_{100}: \mathrm{B}_{0}$ LEDs may have been influenced by the pre-severance light quality of the stock plant environment previously described in the literature (Heins et al., 1980; Hoad and Leaky, 1996; Leaky and StoretonWest, 1992). For instance, Leaky and Storeton-West (1992) reported abachi (Triplochiton scleroxylon K. Schum.) cuttings harvested from stock plants grown under an R:FR ratio of 1.6 to have a greater number of roots per cutting compared with cuttings harvested from stock plants grown under an R:FR ratio of 6.3. However, reduced rooting of wand flower cuttings under LED SSL treatments 


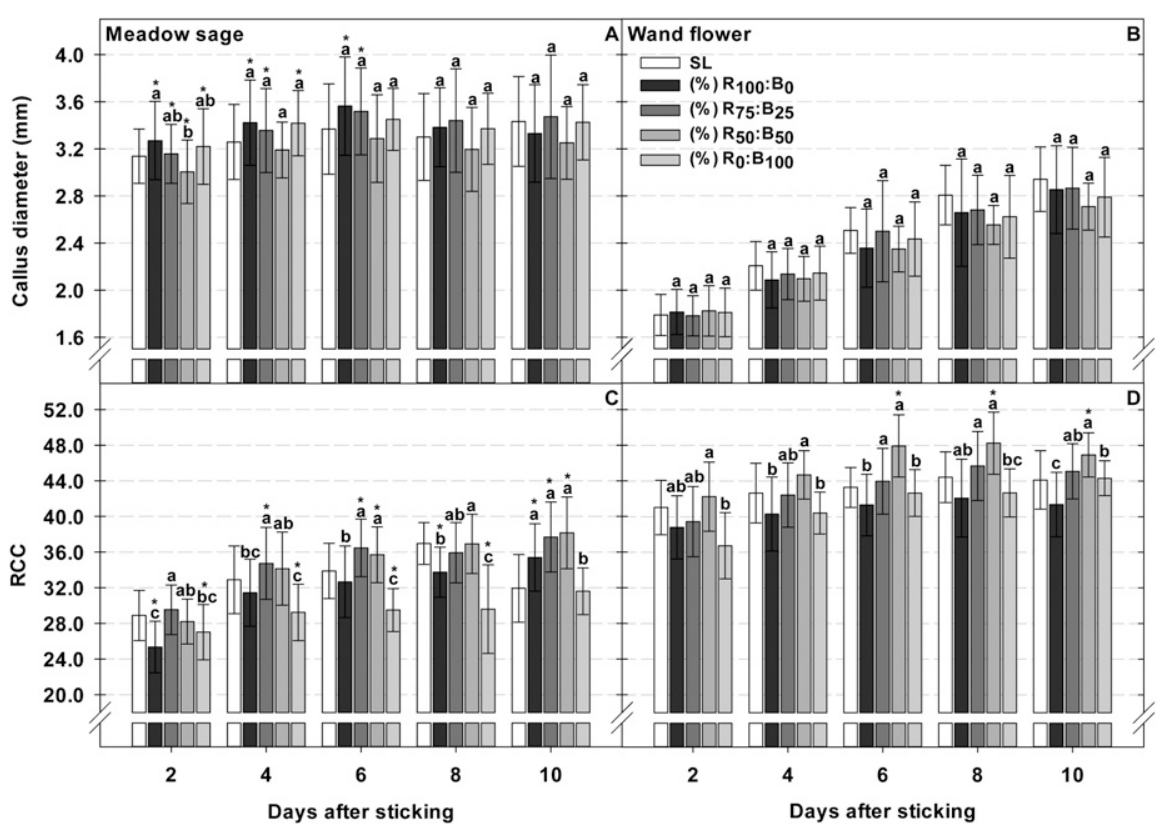

Fig. 2. Callus diameter (A, B) and leaf relative chlorophyll content (RCC) $(\mathbf{C}, \mathbf{D})$ of perennial sage (Salvia nemorosa L. 'Lyrical Blues') and wand flower (Gaura lindheimeri Engelm. and A. Gray 'Siskiyou Pink') cuttings measured at 2, 4, 6, 8, and $10 \mathrm{~d}$ after sticking. Cuttings were propagated in a greenhouse at $21{ }^{\circ} \mathrm{C}$ under ambient solar light and supplemental light (SL) delivered from high-pressure sodium (HPS) lamps or in a growth chamber at $21^{\circ} \mathrm{C}$ under sole-source light (SSL) from light-emitting diodes (LEDs) with red:blue light ratios $(\%)$ of 100:0 $\left(\mathrm{R}_{100}: \mathrm{B}_{0}\right), 0: 100\left(\mathrm{R}_{0}: \mathrm{B}_{100}\right)$, 75:25 $\left(\mathrm{R}_{75}: \mathrm{B}_{25}\right)$, or 50:50 $\left(\mathrm{R}_{50}: \mathrm{B}_{50}\right)$ with a 16 -h photoperiod $(0600$ to $2200 \mathrm{HR})$. Propagation substrate was heated to $24{ }^{\circ} \mathrm{C}$. Error bars indicate \pm SE. Means were separated within each day. For each SSL LED treatment, means sharing lower-case letters are not significantly different by Tukey's honest significant difference (HSD) test at $P \leq 0.05$. A $t$ test was used to compare SSL treatment means to SL treatment means and an asterisk $(*)$ indicates significant difference based on LSD at $P \leq 0.05$.

that provided $\geq 50 \%$ B light could be a result of reduced auxin signaling mediated by the presence of B light. Previous studies suggest B light receptors act through oxidative decarboxylation of auxin, resulting in a reduction of endogenous auxin, thereby delaying or inhibiting rooting (Fuernkranz et al., 1990).

The biological phases that cuttings undergo during propagation were best characterized by Dole and Hamrick (2006). During propagation, unrooted cuttings are not actively growing during stages 0 to 2 (cutting harvest to callusing), but are undergoing several cytological, histological, and physiological changes until stage 3 (rooting). Growth commences at stage 3 with the rise of AR primordia and subsequent ARF, thereby increasing shoot growth (Dole and Hamrick, 2006), and thus biomass accumulation. In the current study, statistical differences in morphology, physiology, and growth that occurred before ARF at 0 to $6 \mathrm{~d}$ and 0 to $2 \mathrm{~d}$ after sticking perennial sage and wand flower cuttings, respectively, could be attributed to the variability of initial cutting size, although cuttings were sorted by stem length, stem caliper, and node and leaf number as suggested by Dole and Hamrick (2006).

Consistent differences were observed in both species at each day for stem length. Stem length of perennial sage measured at 2 to $10 \mathrm{~d}$ after sticking was shortest for cuttings propagated under SSL $\mathrm{R}_{50}: \mathrm{B}_{50}$ LEDs. Generally, these results were comparable to and shorter than cuttings propagated under SSL
$\mathrm{R}_{0}: \mathrm{B}_{100}$ LEDs and $\mathrm{SL}$, respectively. Wand flower stem length was comparable among SSL LEDs at 2 and $8 \mathrm{~d}$, but by $10 \mathrm{~d}$, were shortest when cuttings were propagated under SSL $\mathrm{R}_{50}: \mathrm{B}_{50}$ LEDs. Therefore, perennial sage and wand flower cuttings were most compact under $\mathrm{R}_{50}: \mathrm{B}_{50}$ than those propagated under all other light-quality treatments. Similarly, Gu et al. (2012) reported plantlet height of in vitro propagated anthurium 'Alabama' and 'Sierra' to be shortest under SSL $\mathrm{R}_{50}: \mathrm{B}_{50}$ than $\mathrm{R}_{100}: \mathrm{B}_{0}(658 \mathrm{~nm})$ and $\mathrm{R}_{0}$ : $\mathrm{B}_{100}(460 \mathrm{~nm}) \mathrm{LEDs}$ delivering $40 \mu \mathrm{mol} \cdot \mathrm{m}^{-2} \cdot \mathrm{s}^{-1}$ (DLI of $1.7 \mathrm{~mol} \cdot \mathrm{m}^{-2} \cdot \mathrm{d}^{-1}$ ) for $60 \mathrm{~d}$. Randall and Lopez (2015) reported French marigold (Tagetes patula L. 'Durango Yellow') seedling height to be suppressed and stem caliper to be larger when seedlings were propagated under a combination of SSL R and B LEDs compared with those under SL. Consistently, we found stem caliper of perennial sage to be of comparable size to cuttings under SL when propagated under SSL LEDs providing $\geq 50 \% \mathrm{R}$ SSL, whereas stem caliper of wand flower remained unaffected.

Node number and TLA were similar among all light-quality treatments at $10 \mathrm{~d}$ after sticking. Although, node number of perennial sage exhibited an increasing quadratic response related to decreasing proportions of $\mathrm{B}$ light from SSL $\mathrm{R}_{0}: \mathrm{B}_{100}$ to $\mathrm{R}_{100}: \mathrm{B}_{0}$ LEDs, whereas a comparable quadratic response was found under SL (data not shown). It is speculated that the decrease in node number and thus, number of leaves, is associated with shorter stem lengths found in cuttings under SSL $\mathrm{R}_{50}: \mathrm{B}_{50}$ and $\mathrm{R}_{0}: \mathrm{B}_{100}$ LEDs at $10 \mathrm{~d}$ and may be a result of the absence of FR light that was provided preseverance and a decreasing proportion of $\mathrm{R}$ light provided during propagation (Table 3 ). In general, phytochromes detect the ratio of R:FR light received by plants (Fukuda et al., 2008) and their levels are actively modulated during the life cycle of a plant to optimize light absorption and perception (Clough and Vierstra, 1997). A decrease in the ratio of R: $\mathrm{FR}$, from that of sunlight $(\approx 1.2)$ to values less than 1 , may increase stem elongation (shade avoidance response) and reduce shoot production (Hoad and Leaky, 1996). This is consistent with our results where we found stem length of cuttings to be longer under SSL $\mathrm{R}_{100}: \mathrm{B}_{0}$ LEDs compared with SL. In addition, phytochrome isoforms present in the leaf are controlled by turnover of the photoreceptor on photoconversion from the R-absorbing phytochrome $\left(\mathrm{P}_{\mathrm{r}}\right)$ to the FRabsorbing phytochrome $\left(\mathrm{P}_{\mathrm{fr}}\right)$ (Clough and Vierstra, 1997). The $P_{r}$ form has a half-life of $\approx 1$ week and the $\mathrm{P}_{\mathrm{fr}}$ form is rapidly degraded with a half-life of 1 to $2 \mathrm{~h}$ (Clough and Vierstra, 1997). It is postulated that stock plants were grown under high R:FR ratios, and when cuttings were excised and shipped from offshore production facilities to be received $2 \mathrm{~d}$ later for the experiment, the $\mathrm{P}_{\mathrm{fr}}$ form may have rapidly degraded from a halflife for $\approx 1$ week to $5 \mathrm{~d}$ (Clough and Vierstra, 1997). Once cuttings were placed under their perspective light-quality treatments, $\mathrm{P}_{\mathrm{fr}}$ had converted back to $\mathrm{P}_{\mathrm{r}}$ and in the presence of $\geq 75 \%$ R LED SSL, began to degrade back to the $\mathrm{P}_{\mathrm{fr}}$ form. Whereas under $\geq 50 \% \mathrm{~B}$ LED SSL, the conversion of $\mathrm{P}_{\mathrm{fr}}$ to $\mathrm{P}_{\mathrm{r}}$ did not occur and degradation continued, and thus, resulted in shorter cuttings with fewer nodes, and leaves.

In addition, we observed epinasty in leaves of all perennial sage cuttings propagated under SSL $\mathrm{R}_{100}: \mathrm{B}_{0}$ and $\mathrm{R}_{75}: \mathrm{B}_{25}$ LEDs, which has also been previously reported in banana (Musa xparadisiaca L. 'Nam Dinh'; Nhut et al., 2002) and geranium [Pelargonium zonale (L.) L'Hér. Ex Aiton 'Obic White'; Fukuda et al., 2008]. Nhut et al. (2002) found in the absence of B light in vitro banana plantlets exhibited abnormal growth, whereas normal growth was clearly related to the presence of $\mathrm{B}$ light. Moreover, perennial sage cuttings propagated under SSL $\mathrm{R}_{0}: \mathrm{B}_{100}$ LEDs were found to have less RCC compared with all other light-quality treatments 6 to $10 \mathrm{~d}$ after sticking. This is inconsistent with previous literature, which reported B light from LEDs significantly promoted the accumulation of leaf chlorophyll content in calla lily (Zantedeschia jucunda 'Black Magic'; Jao et al., 2005), florist mum (C. morifolium Ramat. 'Ellen'; Kurilčik et al., 2008), and yarrow (Achillea millefolium L.; Alvarenga et al., 2015). Previous literature indicates that plants generally use B light less efficiently for photosynthesis (Wollaeger and Runkle, 2015), thus limiting the production of photosynthates required for biomass accumulation (Currey and Lopez, 2013). In the 
Table 3. Rooting percentage, stem length, total leaf area (TLA), leaf dry mass (LDM), shoot (stems and petioles) dry mass (SDM), and root dry mass (RDM) of perennial sage (Salvia nemorosa L. 'Lyrical Blues') and wand flower (Gaura lindheimeri Engelm. and A. Gray 'Siskiyou Pink') cuttings. Vegetative cuttings were propagated for $10 \mathrm{~d}$ in a greenhouse at $21^{\circ} \mathrm{C}$ under ambient solar light and supplemental light (SL) delivered from high-pressure sodium (HPS) lamps or in a growth chamber at $21^{\circ} \mathrm{C}$ under sole-source light (SSL) from light-emitting diodes (LEDs) with red:blue light ratios $(\%)$ of 100:0 $\left(\mathrm{R}_{100}: \mathrm{B}_{0}\right), 0: 100\left(\mathrm{R}_{0}: \mathrm{B}_{100}\right)$, $75: 25\left(\mathrm{R}_{75}: \mathrm{B}_{25}\right)$, or 50:50 $\left(\mathrm{R}_{50}: \mathrm{B}_{50}\right)$ with a 16-h photoperiod (0600 to $\left.2200 \mathrm{HR}\right)$. Propagation substrate was heated to $24{ }^{\circ} \mathrm{C}$.

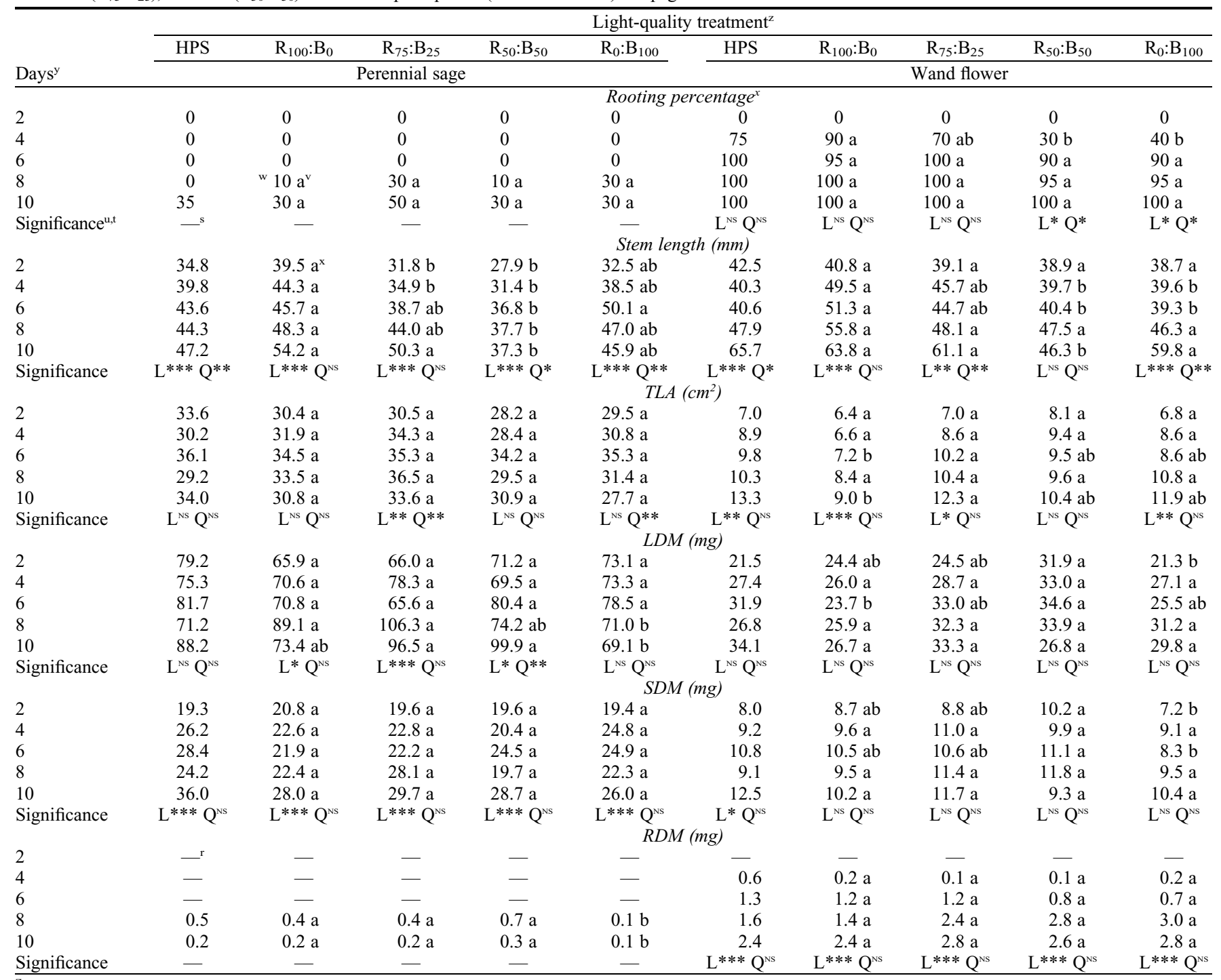

${ }^{\mathrm{z}}$ Ambient solar light and supplemental light (SL) delivered from high-pressure sodium (HPS) lamps in the greenhouse or sole-source light (SSL) light-emitting diodes (LEDs) in the growth chamber.

${ }^{y}$ Days of exposure to SL delivered from HPS lamps in the greenhouse or sole-source light (SSL) delivered from light-emitting diodes (LEDs) in the growth chamber.

${ }^{\mathrm{x}}$ Rooting success $(\%)=$ [number of cuttings rooted $/$ total number of cuttings $\left.\times 100\right]$.

${ }^{\mathrm{w}} \mathrm{A} t$ test was used to compare SL treatment means with SSL treatment mean, thus indicating significant difference based on least significant difference at $P \leq$ 0.05 .

${ }^{\mathrm{v}}$ Within-row means followed by different lower-case letters are significantly different by Tukey's honest significant differences at $P \leq 0.05$.

${ }^{\mathrm{u}} \mathrm{L}=$ linear; $\mathrm{Q}=$ quadratic response across measurement dates $(10 \mathrm{~d})$ at $\mathrm{NS},{ }^{*}, * *$, or $* * *$.

${ }^{\mathrm{t}}$ Nonsignificant (NS) or significant at $P \leq 0.05(*), 0.01(* *)$, or $0.001(* *)$.

${ }^{\mathrm{s}}$ Statistical analysis could not be performed.

${ }^{\mathrm{r}}$ No data available.

current study, perennial sage cuttings under SSL $\mathrm{R}_{0}: \mathrm{B}_{100}$ LEDs were likely not photosynthesizing efficiently. Thus, rather than partitioning carbohydrates into the leaves and stems, they were instead allocating their limited photosynthate supply into AR growth and development. Meanwhile, cuttings under LED SSL providing $\geq 50 \% \mathrm{R}$ light were photosynthesizing efficiently and partitioning carbohydrates into both leaf and root biomass accumulation. This trend of reduced LDM and RDM resulted in lower TDM of perennial sage cuttings propagated under SSL $\mathrm{R}_{0}: \mathrm{B}_{100} \mathrm{LEDs}$.
Wand flower leaf, shoot, and total biomass accumulation increased linearly from 2 to $10 \mathrm{~d}$ under SL, whereas cuttings under LED SSL did not exhibit a statistical response of biomass accumulation to light quality. However, wand flower RDM increased linearly from 2 to $10 \mathrm{~d}$ after stick and was higher under LED SSL providing $\geq 25 \%$ B light compared with SSL $R_{100}: B_{0}$ LEDs and under SL. Increased RDM at $10 \mathrm{~d}$ may be contributed to larger or comparable TLA and RCC found in wand flower cuttings under LED SSL providing $\geq 25 \% \mathrm{~B}$. This is likely because spectral energy distribution of $\mathrm{R}: \mathrm{B}$ light coincides with that of chlorophyll absorption (Goins et al., 1997), thus increasing net photosynthetic rate (Gu et al., 2012), and as a result, wand flower cuttings were likely allocating photosynthates into root growth rather than stem (leaf and shoot) growth and development.

\section{Conclusion}

When our morphological, physiological, and growth data of cuttings at $10 \mathrm{~d}$ of 
propagation under SSL LEDs are compared with SL, we can conclude that there are no negative effects of propagating herbaceous perennials under SSL. Callus growth and AR occurred and increased under all light-quality treatments for both perennial sage and wand flower; however, cuttings propagated under SSL LEDs providing $\mathrm{R}_{50}: \mathrm{B}_{50}$ exhibited shorter stem lengths and higher RDM, which is commercially desirable, as cuttings are less likely to be damaged during shipping and transplanting. Based on our results, we conclude that cutting propagators should establish a DLI of $\approx 4 \mathrm{~mol} \cdot \mathrm{m}^{-2} \cdot \mathrm{d}^{-1}$ delivered from SSL $\mathrm{R}_{50}: \mathrm{B}_{50}$ LEDs during callusing and initial rooting of herbaceous perennial sage and wand flower shoot-tip cutting propagation in a growth chamber or SSL controlledenvironment. Furthermore, we have established a method to quantitatively measure ex vitro callus growth in vegetative shoot-tip cuttings of herbaceous perennials, and with further research, we expect similar outcomes when applied to vegetatively propagated annual bedding plants. Collectively, our results expand the general understanding of light quality on ex vitro callus growth, ARF, and morphology of cuttings. Further investigation of these effects on vegetatively propagated annual bedding plants and other herbaceous perennials is warranted.

\section{Literature Cited}

Ahmed, A.B.A., A.S. Rao, M.V. Rao, and R.M. Taha. 2012. Different wavelengths light to induce physiological changes callus for biosynthesis of gymnemic acid in Gymnema sylvestre. Agro Food Ind. Hi-Tech 23:31-34.

Alvarenga, C.I.A., F.V. Pacheco, S.T. Silva, S.K.V. Bertolucci, and J.E.B.P. Pinto. 2015. In vitro culture of Achillea millefolium L.: Quality and intensity of light on growth and production of volatiles. Plant Cell Tissue Organ Cult. 122:299-308.

Budiarto, K. 2010. Spectral quality affects morphogenesis on Anthurium plantlet during in vitro culture. Agrivita. 32:234-240.

Christiaens, A., M.C. Van Labeke, B. Gobin, and J. Van Huylenbroeck. 2015. Rooting of ornamental cuttings affected by spectral light quality. Acta Hort. 1104:219-224.

Clough, R.C. and R.D. Vierstra. 1997. Phytochrome degradation. Plant Cell Environ. 20:713-721.

Currey, C.J. and R.G. Lopez. 2013. Cuttings of Impatiens, Pelargonium, and Petunia propagated under light-emitting diodes and high-pressure sodium lamps have comparable growth, morphology, gas exchange, and post-transplant performance. HortScience 48:428-434.

Currey, C.J., V.A. Hutchinson, and R.G. Lopez. 2012. Growth, morphology, and quality of rooted cuttings of several herbaceous annual bedding plants are influenced by photosynthetic daily light integral during root development. HortScience 47:25-30.

da Costa, C.T., M.R. de Almeida, C.M. Ruedell, J. Schwambach, F.S. Maraschin, and A.G. Fett-Neto. 2013. When stress and development go hand in hand: Main hormonal controls of adventitious rooting in cuttings. Plant Sci. 133:1-19.
Dole, J.M. and D.J. Hamrick. 2006. Propagation basics, p. 3-16. In: J.M. Dole and J.L. Gibson (eds.). Cutting propagation - A guide to propagating and producing floriculture crops. Ball Publishing, Batavia, IL.

Fonteno, W.C., C.T. Harden, and J.P. Brewster. 1995. Procedures for determining physical properties of horticultural substrates using the $\mathrm{NC}$ State University porometer. North Carolina State Univ., Hort. Substrates Lab., Raleigh, NC.

Fuernkranz, H.A., C.A. Nowak, and C.A. Maynard. 1990. Light effects on in vitro adventitious root formation in axillary shoots of mature Prunus serotina. Physiol. Plant. 80:337-341.

Fukuda, N., M. Fujita, Y. Ohta, S. Sase, S. Nishimura, and H. Ezura. 2008. Directional blue light irradiation triggers epidermal cell elongation of abaxial side resulting in inhibition of leaf epinasty in geranium under red light condition. Scientia Hort. 115:176-182.

Goins, G.D., N.C. Yorio, M.M. Sanwo, and C.S Brown. 1997. Photomorphogenesis, photosynthesis and seed yield of wheat plants grown under red light-emitting diodes (LEDs) with and without supplemental blue light. J. Expt. Bot. 48:1407-1413.

Gu, A., W. Liu, C. Ma, J. Cui, R.J. Henny, and J. Chen. 2012. Regeneration of Anthurium andraeanum from leaf explants and evaluation of microcutting rooting and growth under different light qualities. HortScience 47:88-92.

Hanan, J.J. 1998. Structure: Locations, styles, and covers, p. 15-90. In: J. Hanan (ed.). Greenhouse: Advanced technology for protected horticulture. CRC Press, Boca Raton, FL

Heins, R.D., W.E. Healy, and H.F. Wilkins. 1980. Influence of night lighting with red, far red and incandescent light on rooting of Chrysanthemum cuttings. HortScience 15:84-85.

Hoad, S.P. and R.R.B. Leaky. 1996. Effects of preseverance light quality on the vegetative propagation of Eucalyptus grandis W. Hill ex Maiden. Trees 10:317-324.

Hutchinson, V.A., C.J. Currey, and R.G. Lopez. 2012. Photosynthetic daily light integral during root development influences subsequent growth and development of several herbaceous annual bedding plants. HortScience 47:856-860.

Ikeuchi, M., Y. Ogawa, A. Iwase, and K. Sugimoto. 2016. Plant regeneration: Cellular origins and molecular mechanisms. Development 143:1442-1451.

Jao, R.-Y., C.-C. Lai, W. Fang, and S.-F. Chang. 2005. Effect of red light on the growth of Zantedeschia plantlets in vitro and tuber formation using lightemitting diodes. HortScience 40:436-438.

Korczynski, P.C., L. Logan, and J.E. Faust. 2002. Mapping monthly distribution of daily light integrals across the contiguous United States. HortTechnology 12:12-16.

Kurilčik, A., R. Miklusyte-Canova, S. Dapkuniene, A. Zilinskaite, G. Kurilčik, G. Tamulaitis, P. Duchovskis, and A. Zukauskas. 2008. In vitro culture of Chrysanthemum plantlets using lightemitting diodes. Cent. Eur. J. Biol. 3:161-167.

Leaky, R.R.B. and R. Storeton-West. 1992. The rooting ability of Triplochiton scleroxylon cuttings: The interactions between stock plat irradiance, light quality and nutrients. For. Ecol. Mgt. 49:133-150.

Lim, Y.J. and S.H. Eom. 2013. Effects of different light types on root formation of Ocimum basilicum L. cuttings. Scientia Hort. 164:552-555.

Lopez, R.G. and E.S. Runkle. 2008. Photosynthetic daily light integral during propagation influences rooting and subsequent growth and development of New Guinea Impatiens and Petunia. HortScience 43:2052-2059.

Mottley, J. and B. Keen. 1987. Indirect assessment of callus fresh weight by non-destructive methods. Plant Cell Rpt. 6:389-392.

National Oceanic and Atmospheric Administration. U.S. Dept. of Commerce. 2016. State of the climate: National overview for annual 2015. Natl. Ctrs. Environ. Info., Asheville, NC. 3 Oct. 2016. <http://www.ncdc.noaa.gov/sotc/ national/201513>.

Nhut, D.T., L.T.A. Hong, H. Watanabe, M. Goi, and M. Tanaka. 2002. Growth of banana plantlets cultured in vitro under red and blue light-emitting diode (LED) irradiation source. Acta Hort. 575:117-124.

Olschowski, S., E.-M. Geiger, J.V. Herrmann, G. Sander, and H. Grüneberg. 2016. Effects of red, blue, and white LED irradiation on root and shoot development of Calibrachoa cuttings in comparison to high-pressure sodium lamps. Acta Hort. 1134:245-250.

Owen, W.G. and R.G. Lopez. 2016. Perennial propagators' successes and challenges: Results of a national survey. GreenhouseGrower 34:56-60.

Pfaff, W. and P. Schopfer. 1974. Phytochrom-induzierte regeneration von adventivwurzeln beim senfkeimling (Sinapis alba L.). Planta 117:269-278.

Pfaff, W. and P. Schopfer. 1980. Hormones are no causal links in phytochrome-mediated adventitious root formation in mustard seedlings (Sinapis alba L.). Planta 150:321-329.

Pilon, P. 2006. Perennial propagation, p. 249-296. In: P. Pilon (ed.). Perennial solutions: A grower's guide to perennial production. Ball Publishing, Batavia, IL

Randall, W.C. and R.G. Lopez. 2015. Comparison of bedding plant seedlings grown under sole-source light-emitting diodes (LEDs) and greenhouse supplemental lighting from LEDs and high-pressure sodium lamps. HortScience 50:705-713.

Sager, J.C., W.O. Smith, J.L. Edwards, and K.L. Cyr. 1988. Photosynthetic efficiency and phytochrome photoequilibria determination using spectral data. Amer. Soc. Agr. Eng. 31:1882-1889.

Sathyanarayana, B.N. and D.B. Varghese. 2007. Plant regeneration from callus culture, p. 109 121. In: B.N. Sathyanarayana and D.B. Varghese (eds.). Plant tissue culture: Practices and new experimental protocols. I.K. Intl. Publishing House, New Delhi, India.

Scoggins, H.L. 2006. Cutting propagation of herbaceous perennials, p. 173-185. In: J.M. Dole and J.L. Gibson (eds.). Cutting propagation-A guide to propagating and producing floriculture crops. Ball Publishing, Batavia, IL.

Stoutemyer, V.T. and F.L. O'Rourke. 1946. Rooting cuttings and germinating seeds under fluorescent and cold cathode light. Proc. Amer. Hort. Sci. 48:309-325.

U.S. Department of Agriculture. 2016. Floriculture crops 2015 summary. Natl. Agr. Stat. Serv., Washington, D.C. 30 Sept. 2016. <http://usda. mannlib.cornell.edu/usda/current/FlorCrop/ FlorCrop-04-26-2016.pdf>.

Van Dalfsen, P. and L. Slingerland. 2012. Stekken onder LED-verlichting 2. Praktijkonderzoek Plant \& Omgeving, Lisse, The Netherlands.

Wollaeger, H.M. and E.S. Runkle. 2015. Growth and acclimation of impatiens, salvia, petunia, and tomato seedlings to blue and red light. HortScience 50:522-529. 